\title{
Research on Online Learning Behavior Data Model Based on Network Teaching Platform
}

\author{
Zhang Guoming \\ Nanchang Institute of Science \& Technology, Nanchang, 330108, China
}

Keywords: network teaching platform; online learning; behavior analysis; Web visualization; adaptive

\begin{abstract}
With the development of information technology and the increasing thirst for knowledge, web-based learning platform arises at the historic moment. In order to improve the efficiency of learners and provide a more humane learning platform, this paper analyses the learning behavior analysis model of online learning users, puts forward the learning behavior analysis model of web-based network teaching platform, and starts with the construction of network teaching platform, puts forward the learning behavior analysis of network teaching platform. Finally, the paper discusses the role of learning behavior analysis in improving learners 'personalized learning and self-adaptive ability of online learning. It has a certain practical significance for improving online learners' learning efficiency and distance learning quality.
\end{abstract}

\section{Introduction}

The reform of education system and the progress of computer network technology have promoted the formation and development of network teaching mode. From the perspective of educational history, the development of education is inseparable from the reform of the system, and is also indispensable to the support of science and technology. Nowadays, the highly developed network technology has laid a solid foundation for the development of network teaching mode. From the current network teaching experience, the network learning environment is open and the binding is weak, and this time, through the exploration of the network teaching platform, the aim of this study is to study the model of network learning behavior, in order to change the network education. Leather provides theoretical reference.

\section{The online learning behavior analysis model based on network teaching platform}

The study of learning analysis model is based on the learning demand oriented, in order to optimize the learning intervention and learning resources. It can be analyzed and studied by the bottom-up modeling method. The online learning behavior analysis model is divided into three levels, the first layer is the data layer, and the layer is the network platform online learning users in the learning time. The second layer is the mechanism layer, which can analyze the techniques and methods of optimizing the allocation of learning resources and the methods of learning intervention. The result layer reflects the relationship between the relevant data and the learners, and expresses the influence of the learning analysis on the learning results.

As shown in Figure 1, the database of user online learning behavior can be established by using the database of network teaching platform. Then the analysis mechanism is used to visualize and feedback the learning behavior. In the end, the learning behavior of the learners can be adjusted by means of intervention, and the learning efficiency of online learning users online is improved. Fruit. According to the network teaching platform, the learning behavior data can be excavated by Web technology, including Web content mining, Web structure mining and Web using record mining. The overall framework is shown in Figure 2. 


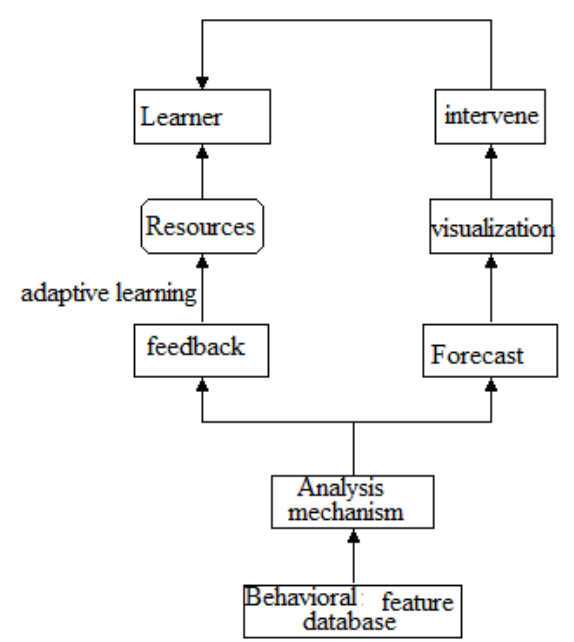

Fig. 1 The model of learning behavior analysis

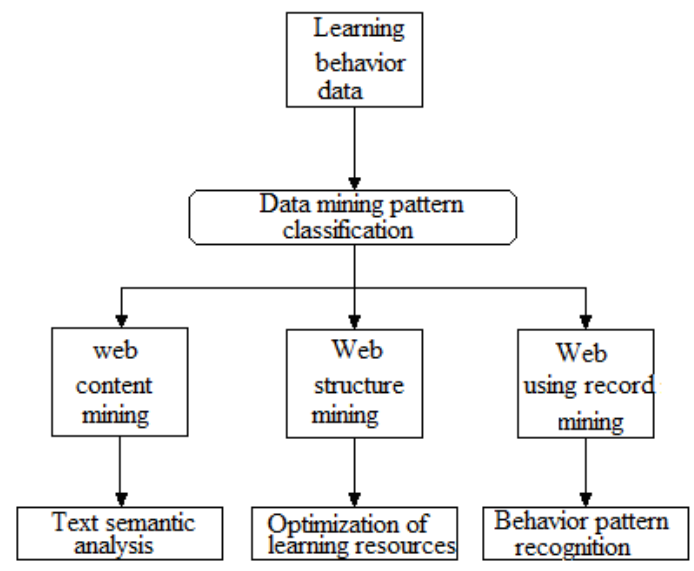

Fig. 2 The learning behavior analysis model based on network teaching platform

As shown in Figure 2, Web content mining is mainly to excavate the content of learning behavior of network teaching platform, including the process of content retrieval, filtering, clustering and so on. It can use text semantic analysis technology to convert the content into the data that can be processed by computer, and finally for learning and analyzing service. The Web structure mining is mainly from the learning level. Beginning with the organizational structure of Taiwan, this paper finds the best relationship model from the complex multi-dimensional relationship and constructs the learning function recommendation for teaching. The last is the mining of Web using records. Online learning will leave a series of access and interactive information after accessing the network teaching platform. From it, effective information can be extracted to analyze the learning behavior, and then the online learners are intervened to improve the learner's personality chemistry and self-adaptive ability.

\section{The construction of network teaching platform based on learning analysis model}

In order to realize the learning behavior analysis of online users, the acquisition of learning behavior information should be taken into consideration in the construction of network teaching platform, and the relevant information recording interface for each function module of the network teaching platform is designed under the condition of the basic realization of the platform function. The network learning behavior monitoring system is an important part of the learning behavior analysis system. In the design, the system's behavior records and statistical analysis can be refined, as much as possible, and the framework of the monitoring system is shown in Figure 3. 


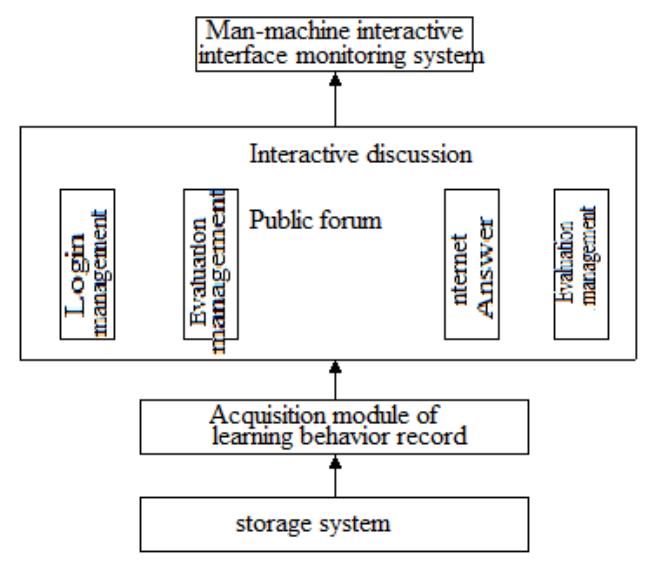

Fig.3 The network learning behavior monitoring system

As shown in Figure 3, the network learning behavior monitoring system has a unified data acquisition module. After the completion of the data collection, it can be stored in the storage system for statistical analysis and visualization. In addition to recording the learning resources and interactive learning, the Department also records the logon and each course. In order to improve the network teaching system and improve the self-adaptive learning ability of the users, a series of behavioral records, such as learning time, are made. In order to realize the visualization of online learning behavior, a special user learning behavior visualization system can be designed, as shown in Figure 4.

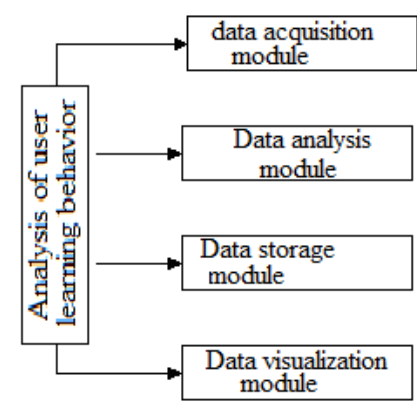

Fig.4 user online learning behavior visualization system

As shown in Figure 4, the visualization system for online learning behavior of users consists of four modules, including data acquisition module, data storage module, data analysis module and data visualization module, and the analysis dimension of online user learning behavior is shown in Figure 5.

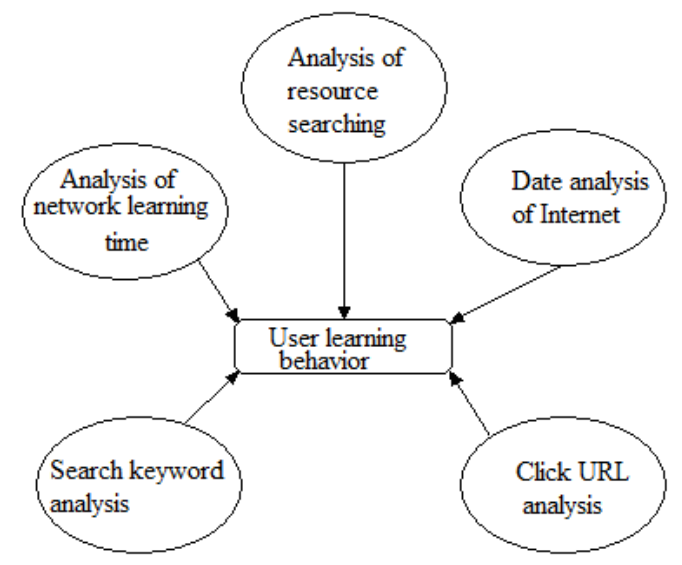

Fig.5 analysis dimension of online user learning behavior

The analysis of online user learning behavior is mainly composed of five analysis modules, including network learning time, search amount, Internet date, keyword, URL analysis and so on. 
Through visualization technology, we can show the content of learning and analysis of the user's search volume and key words, and the realization tools of visual function are based on the base. In the visualization tool of Web technology, the background database of visual display uses the MySQL database, and it also supports the query function of the visual content, thus greatly facilitated the analysis of the user's network learning behavior.

\section{The design of web-based learning mode based on learning behavior analysis}

The analysis of online learning behavior is ultimately for the optimization of network teaching platform resources and the service of learning intervention, so that online learning users can get an efficient and easy learning environment, make the network learning environment more humanized, and the learner's self-adaptive learning ability is stronger.

Online learning behavior analysis can provide personalized learning plan and guidance for online learning users. Different learners can change their learning plans according to their own different conditions and learning progress, and refer to the results of visual learning behavior analysis provided by the network learning platform, and adjust their learning plans in real time.

The online learning behavior analysis can improve the learner's self-adaptive ability. In the process of online learning, only when the user adapts to the network learning environment, the learners can learn with a good state of mind. When the learners have difficulties, the visual results of the analysis of online learning behavior can provide more humanized hints and help. Online learning users adapt to the learning environment to the greatest extent.

\section{Conclusion}

In order to improve the self-adaptive ability of online users and meet their personalized learning needs, based on the network teaching platform, the construction scheme of network teaching platform with visual function analysis and personalized guidance is proposed. Through research and analysis, it is found that the analysis of learning behavior can make use of the data statistics of the network platform and the visualization of Web. The personalized service can be improved by the intervention of distance teaching and the self-adaptive ability of the students. Finally, the analysis of learning behavior can improve the self-adaptive ability of the learners' individualized learning and network learning. It is of great significance to optimize the resources of network teaching platform and enhance the students 'adaptive ability.

\section{Acknowledgement}

The work was supported by two subtopics from the science and technology research project of Jiangxi Provincial Department of Education in 2017 with the project number GJJ171099 and the project name Modeling and research of user online learning behavior analysis model in big data environment. One of the subtopics is Research on user online learning behavior analysis model under big data environment, and another is Analysis framework design of user's online learning behavior under big data environment.

\section{References}

[1] Liu Mengchao, Xiao Jirong, Chen Rong. Application of data mining in user behavior analysis. Computer knowledge and technology, 2012, 31 (04): 7409-7412.

[2] Pan Feng Nan. Analysis and Research on user behavior of campus network [J]. Journal of Yangtze University, 2013, 23 (02): 1403-1409.

[3] Li Changxian. Research on school users' network behavior classification system [J]. Statistics and management, 2013, 04 (061):144-145.

[4] Duan Jinju, Yu Shengquan, Wu Pengfei. Research perspective and evolution trend of socialized 
learning -- Analysis Based on open knowledge community[J]. Distance education magazine.2016 (03)

[5] He Gao.visual language learning from the perspective of visual representation and teaching application [J]. Journal of distance education. 2015 (02):55-57.

[6] Wang Zheng. The effective teaching of College English classroom under the constructivist learning theory -- Taking the fourth "foreign language society Cup" national college foreign language teaching competition for example [J]. Foreign language circle. 2014 (04):29-35.

[7] Fu Li, Zhao Jian. Research on the application of virtual reality technology in education and teaching [J]. Digital technology and application,2012 (10):11-16.

[8] Wu Shufang. The comparison and Enlightenment of the construction and research of language autonomous learning centers at home and abroad [J]. Laboratory research and exploration,2012 (08):99-105.

[9] Cheng Suping, Wang Tingting. The cognitive flexibility theory and its implications for teaching practice [J]. Journal of Tianjin Normal University (Basic Education Edition), 2011 (01):72-75. 